\title{
IMPACTO DE LAS IDEOLOGÍAS EN EL RESPETO DE LOS DERECHOS HUMANOS EN EL SIGLO XX*
}

El 7 de diciembre de 2004 se llevó a efecto el seminario "Ejército y Derechos Humanos: Compromiso para el siglo XXI", por iniciativa del Ejército de Chile. El seminario, que se realizó en la Escuela Militar, en Santiago, contó con la participación de destacados panelistas, así como con la asistencia de autoridades de los tres poderes del Estado y representantes de organizaciones del mundo civil y militar. La clausura del seminario estuvo a cargo del Comandante en Jefe del Ejército, general Juan Emilio Cheyre, cuyo discurso se incluye en esta edición en el documento "Informe de la Comisión Nacional sobre Prisión Política y Tortura, y respuestas institucionales".

En las páginas que siguen se reproducen las ponencias del senador socialista Ricardo Núñez y del abogado y miembro del partido Renovación Nacional, Andrés Allamand, presentadas durante el foro "El impacto de las ideologías en el respeto de los derechos humanos en el siglo XX" que tuvo lugar en el marco del seminario.

* Véanse en esta misma edición un extracto del Informe de la Comisión Nacional sobre Prisión Política y Tortura, así como respuestas al mismo de las distintas ramas de las fuerzas armadas y de orden, y de instituciones de la judicatura.

Para acceder a otros documentos y artículos publicados en Estudios Públicos sobre el tema de los derechos humanos e historia política de Chile, dirigirse a www.cepchile.cl 


\section{PONENCIA EN FORO \\ "EL IMPACTO DE LAS IDEOLOGÍAS EN EL RESPETO DE LOS DERECHOS HUMANOS EN EL SIGLO XX”*}

\section{Ricardo Núñez}

Con satisfacción he aceptado la invitación con que me honrara el Comandante en Jefe del Ejército, General Juan Emilio Cheyre, a participar en este importante seminario. Saludo a quienes han tenido la responsabilidad de organizarlo y espero que el esfuerzo realizado contribuya a fortalecer las relaciones cívico-militares en nuestro país.

Éste se realiza en un momento particularmente relevante para la historia patria. El documento recientemente entregado a la opinión pública por el señor Comandante en Jefe del Ejército, denominado "Ejército de Chile: Fin de una Visión”, así como el Informe sobre la Prisión Política y Tortura, elaborado por una comisión encabezada por Monseñor Valech y que el Presidente Ricardo Lagos puso a conocimiento del país a través de una emotiva alocución televisiva**, nos pone ante la obligación de transparentar nuestra conciencia, hacer más diáfano el debate político y académico y retomar con fuerza nuestra historia para iluminar con decisión nuestro futuro.

Se me ha pedido que exponga acerca del impacto de las ideologías en relación al respeto de los derechos humanos durante el siglo pasado. Permítanme hacer previamente dos precisiones: el siglo que nos preocupa en realidad se extiende desde la Primera Guerra Mundial en 1914 y la caída del comunismo en 1989. Es lo que el historiador Eric Hobsbawm, denomina el "siglo corto" y es, a juicio de muchos, el más cruel y mortífero de toda la historia de la humanidad.

El concepto ideología, a su vez, posee entre los cientistas sociales diversas acepciones. Para mí, ellas son construcciones paradigmáticas que el hombre pretende materializar en una realidad concreta y que prefiguran un futuro ideal. Durante el siglo XX, los intereses y las pretensiones hege-

* Texto completo de la exposición del senador y miembro del Partido Socialista, Ricardo Núñez Muñoz, en el foro sobre el impacto que tuvieron las ideologías en el respeto de los derechos humanos en el siglo XX, en el marco del seminario "Ejército y Derechos Humanos, Compromiso para el Siglo XXI" organizado por el Ejército de Chile en la Escuela Militar, Santiago, el 7 de diciembre de 2004. (N. del E.)

** Tanto el documento "Ejército de Chile: Fin de una Visión", como extractos del Informe de la Comisión Nacional sobre Prisión Política y Tortura (conocido también como Informe Valech), y el texto de la alocución del Presidente Lagos (que corresponde al Prólogo del Informe), se reproducen en esta edición en el documento "Informe de la Comisión Nacional sobre Prisión Política y Tortura, y respuestas institucionales”. (N. del E.) 
mónicas de las grandes potencias se disputaron campos de influencias en todos los ámbitos. No existió espacio — ni en la esfera política, económica o cultural — donde ellas no intentaran establecer sus "marcas" — como lo hiciera en el pasado el imperio romano- para asegurar así su zona de influencia, su espacio vital, su área de acción donde pudieran campear sin límite alguno. En 1914, las luchas por conquistar dichos espacios condujeron al mundo a la Primera Guerra Mundial.

Los imperios existentes a la época se confrontaron en una guerra brutal que culminaría con la destrucción del Imperio Austro-Húngaro, la firma de Tratado de Versalles y la Revolución Rusa. Tanto Inglaterra, como Francia y en menor medida Italia, y la potencia emergente de Estados Unidos, se constituyeron en los ejes vertebradores de un mundo donde el poder de uno se equilibró, de manera crecientemente inestable, con el poder del otro.

Poder y contra-poder fue la fórmula que vivió el mundo durante esa primera parte del siglo XX. Mientras se reponía de las heridas de la guerra y hacía frente a las indemnizaciones que debió pagar a los países vencedores, Alemania se rearmaba lentamente para una nueva contienda bélica. América Latina, por su parte, al igual que Asia y África, jugaba un rol secundario. Era un testigo pasivo de un nuevo mundo, sin que en su configuración tuviera participación, salvo de manera marginal. Tras un breve interregno —en general positivo para la causa democrática - el mundo nuevamente se encaminó a la guerra. Esta vez, ella abarcó prácticamente todos los continentes.

Pocos pudieron marginarse de sus consecuencias. Nuestro país tampoco pudo escapar a la dramática lógica a la que se encaminó la humanidad. Se desató así la Segunda Guerra Mundial. Ella costó la vida a más de 52 millones de seres humanos y pérdidas materiales incalculables. Europa quedó destruida política y materialmente. La Alemania de Hitler y la Italia de Mussolini fueron aplastadas por las fuerzas aliadas. Japón se rindió bajo el impacto atroz y cruel de la bomba atómica. El mundo vio erigirse una cortina de hierro que habría de dividirlo hasta finales del siglo. Estados Unidos y la Unión Soviética se transformaron en las dos grandes superpotencias vencedoras.

Ellas dominarían el escenario mundial sin contrapeso. Se repartirían extensas zonas de dominio e influencia. Del equilibrio inestable de la preguerra se pasó al equilibrio atómico. De un mundo multipolar se pasó a uno bipolar. Sin declararse jamás formalmente, se desencadenó otra guerra: la "Guerra Fría". La humanidad se dividió entre buenos y malos; entre capitalistas y comunistas; entre la civilización judeo-cristiana y la civiliza- 
ción atea y materialista; entre los aliados de Estados Unidos y los de la Unión Soviética. De esta perversa lógica nadie pudo excluirse. Ni siquiera nuestro país. La Guerra Fría se instaló en casa con el último disparo de la contienda mundial.

Nos marcó a fuego y en medio de ella la historia patria se estremeció de manera dramática con los acontecimientos desencadenados a partir del 11 de septiembre de 1973. En medio de este proceso histórico, ¿qué papel jugaron las ideologías? ¿Cuáles fueron las motivaciones últimas que animaron a los actores de este período aciago? Responder estas interrogantes es difícil. Debemos tener presente que todas las acciones emprendidas por los países e imperios existentes en esta época, se recubrieron de justificaciones ideológicas o exhibieron sus pretensiones hegemónicas a partir de consideraciones ideales.

Permítanme hacer una brevísima descripción de aquellas que más significación alcanzaron durante este período. Después de la Primera Guerra Mundial, los principios inspiradores de la Revolución francesa y la irrupción que bajo su influjo hicieran los movimientos liberales, se constituyeron en factor esencial para la universalización de los principios básicos de la democracia. El racionalismo positivista, propio del liberalismo, tuvo la virtud de dotar a la institucionalidad política de un fuerte contenido laico en el cual prevaleciera un armónico equilibrio entre los poderes del Estado.

Derechos fundamentales como el de reunión, de asociación, de elegir y ser elegido a través del voto popular, se expandieron por todo el mundo occidental. Se consolidaron los partidos políticos en tanto intermediarios de la sociedad y el Estado. En el ámbito internacional se constituyó la Sociedad de las Naciones, como una organización destinada a resolver y alejar la guerra de la vida de los pueblos.

Este alentador proceso se vio afectado por la violenta irrupción de totalitarismos como los encabezados por Hitler, Mussolini y Stalin. A pesar del encandilamiento que éstos ejercieran en algunos sectores de nuestra vida política y de la breve dictadura del General Ibáñez, Chile se mantuvo dentro de los límites propios de la democracia. El movimiento socialista, por su parte, vivió un vigoroso proceso de expansión por los más diversos rincones del mundo.

El pensamiento del filósofo alemán Carlos Marx impregnó fuertemente las luchas sociales y políticas del movimiento obrero y de otros sectores populares, afectados por la revolución industrial y el desarrollo del capitalismo. La miseria, la marginalidad y la explotación del trabajo asalariado coadyuvaron al despliegue de las ideas socialistas. Éstas, sin embargo, desde sus inicios, vivieron un proceso de división que culminó en el 
establecimiento de dos grandes corrientes. Una inspirada en la revolución rusa y en el fundador del Estado soviético, Vladimir Ilich Lenin, y otra que se inspiró en pensadores europeos como Friedrich Ebert, Eduard Bernstein y Kaustky. Mientras Lenin propiciaba la instauración de una ideología estatal inspirada en una específica interpretación de las ideas de Marx; los otros, bajo similar inspiración, entendieron que los valores y principios de la democracia no eran incompatibles con la construcción del socialismo.

Para el primero, el socialismo se entendía como un dogma de Estado y para los otros como un proceso de organización de la sociedad y la economía donde la igualdad no debía sacrificar la libertad. Para Lenin los valores de la democracia eran un medio y para los otros un fin en sí mismo. En la experiencia chilena, el movimiento socialista tuvo desde principios de siglo dos grandes corrientes. Una expresada por el Partido Comunista y otra por el Partido Socialista. Mientras el Partido Comunista tendió a seguir estrictamente el denominado modelo soviético; el Partido Socialista buscó constituirse en un gran movimiento nacional y popular, tal como lo expresaran sus fundadores, entre otros, Óscar Schnake, el Comodoro del Aire Marmaduque Grove, Eugenio Matte Hurtado y el que fuera rector de la Universidad de Chile, don Eugenio González Rojas.

Este último, en sus ácidas polémicas contra el estalinismo, sostuvo, en 1947, que el socialismo era esencialmente humanista y que "ningún fin puede obtenerse a través de medios que lo niegan: la educación de los trabajadores para el ejercicio de la libertad tiene que hacerse en un ambiente de libertad". Durante el transcurso del siglo XX, surgió otra corriente ideológica que marcó fuertemente su devenir. El nacionalsocialismo y el fascismo emergieron como respuesta al desarrollo de las ideas liberales y socialistas que vivía Europa.

Sus fuentes de inspiración fueron la exacerbación de los elementos culturales de carácter nacionalista, la convicción en la superioridad de una raza por sobre otras y en el entendido que la conducción política del Estado debía estar en manos del más fuerte. Nutridas de la pobreza de ciertas capas sociales y de una visión autoritaria que impregnaba a su elite política, ambas corrientes se expandieron por diversos países europeos y de América Latina, en particular, luego de la Gran Depresión de la economía mundial del año 1929.

En Chile, el Movimiento Nacional Socialista liderado por González von Marées, en la década del 30 y 40, y el Movimiento Nacionalista Patria y Libertad, fundado a principios de los 70, fueron su máxima expresión. Las ideas conservadoras, mientras tanto, mantuvieron durante gran parte del siglo una fuerte presencia. La Iglesia católica y especialmente la institu- 
ción papal fueron su principal baluarte. Bajo el papado de León XIII y la Encíclica Rerum Novarum, se inició un proceso de cambio de las ideas del tradicionalismo conservador.

La Iglesia aceptó que la pobreza y la marginalidad, en la que habían devenido enormes masas de seres humanos, tenían sus causas en la manera cómo se organizaba la economía, la sociedad y el Estado. Sus enseñanzas tuvieron un fuerte impacto. En Chile, un grupo de jóvenes, conmovidos por la miseria y la desigualdad, en la que vivían vastos sectores de chilenos, se separan del Partido Conservador y fundan bajo la inspiración de dicha Encíclica, la Falange Nacional, la que daría paso, en la década del 50, a la Democracia Cristiana. Ésta asumiría las enseñanzas del Papa Juan XXIII, de la Encíclica Pacem in Terris, del Concilio Vaticano II, y la influencia del pensador francés Jacques Maritain.

En esta apretada síntesis, nos queda por revisar una última ideología. En el contexto de la guerra fría y frente al avance de las ideas fundadas en la Revolución Soviética, la instauración de la República Popular China y la consolidación del campo socialista en Europa del Este, las potencias occidentales y los Estados Unidos no podían quedar impávidos. Las guerras de Corea y Vietnam acrecentaron el denominado "peligro comunista".

La Doctrina de la Seguridad Nacional, incubada en los centros académicos del Pentágono y la CIA, fue la respuesta a ese inmenso desafío. Según ésta, todos los países que no formaban parte de la zona de influencia soviética corrían el peligro de ser objeto de subversión interna, orquestada desde Moscú. Los países subdesarrollados, en especial, se encontrarían inermes e incapaces de enfrentarla. Por tanto, no quedaba otra alternativa. Era menester hacerle frente, aunque para ello fuera necesario el uso de la violencia y eventualmente promover la intervención de las Fuerzas Armadas de esos países.

En el fondo, esta concepción sostenía que ante un peligro de tal envergadura, la democracia, la libertad y los derechos humanos podían ser conculcados. Los golpes de Estado que terminaron con las democracias en países como Argentina, Uruguay y Chile, y otros más lejanos como el Congo Belga, Filipinas e Indonesia, se explican bajo esta doctrina. Entre tanto, ¿qué pasaba en el campo de los derechos humanos? Como está dicho, el mundo del siglo XX, no sólo sufrió los horrores de dos guerras mundiales, sino que debió enfrentar la emergencia de doctrinas totalitarias y la confrontación ideológica a que nos arrastró la Guerra Fría. En este cuadro es interesante constatar que, a pesar de aquello, la sensatez y la humanidad de los pueblos no fueron aplastadas. 
Los derechos fundamentales del hombre dieron un paso sustantivo en la perspectiva de hacer de ellos la base sobre la cual ha de erigirse un mundo más humanizado que lo aleje definitivamente de la barbarie y la destrucción. La naciente Organización de las Naciones Unidas alcanzó un éxito sin precedentes. Junto al proceso de descolonización, bajo su amparo se proclamó, el año 1948, la Declaración Universal de los Derechos Humanos.

$\mathrm{Su}$ Preámbulo es una pieza magistral. Según éste, todos los seres humanos nacen libres e iguales, independientemente de su condición, sexo, raza, religión u opinión política. Los derechos humanos se establecieron así, como un atributo esencial de la dignidad humana. Independientemente de los obstáculos puestos por los Estados Unidos y por la propia Unión Soviética, la mayor parte de los países se conjugaron en torno a una sola voluntad: hacer posible que estos derechos se internalizaran en la conciencia civilizada de todos los hombres y mujeres de buena voluntad. Por ello, ese mismo año la Asamblea General de la ONU pidió a todos sus miembros distribuirla y difundirla por doquier.

Fruto de esta trascendental declaración, se reconocieron como valor universal, derechos fundamentales tales como la igualdad ante la ley; la libertad de asociación, reunión y expresión; el derecho a no ser sometido a torturas ni a penas o tratos crueles, inhumanos o degradantes, y a no ser arbitrariamente detenido, preso ni desterrado. En fin, y como sostén de todos ellos, el derecho a la vida, a la libertad y la seguridad. La humanidad había avanzado así, hacia un estadio superior en su desarrollo civilizatorio.

Señoras y señores:

Al concluir, no puedo dejar de hacer una reflexión que nos incumbe directamente como chilenos: estos derechos, tan caros para la humanidad, no fueron debidamente aquilatados por todos nosotros, actores de hechos y acontecimientos acaecidos a fines del 60 y principios del 70 . Permítaseme hacer una afirmación dolorosa. Ninguna fuerza política había internalizado profundamente los valores de los Derechos Humanos. Ellos no estaban en el currículum de nuestras principales instituciones educativas. No formaban parte de nuestro acervo cultural.

Esto permitió que la sobre-ideologización, la polarización política, la pérdida de la convivencia cívica, las visiones totalizantes de la vida, se convirtieran en el sustrato que posibilitó que, en 1973, se clausurara nuestra democracia a través del golpe de Estado que encabezaran las Fuerzas Armadas y de Orden y que terminó con la vida del Presidente Salvador Allende y La Moneda bombardeada. 
Muchos nos hemos preguntado: ¿estaba la sociedad chilena en condiciones de evitar el golpe de Estado? Está claro que la vida política se había degradado a un extremo inimaginable. Que quienes tenían posibilidad de impedirlo no lo hicieron o no tuvieron la fuerza para hacerlo. Soy de los que creo que no hubo voluntad suficiente. Que la vida en sociedad se había hecho malsana. Que la confrontación ideológica expresada en consignas como "avanzar sin transar" y "Yakarta viene", reflejaba una profunda odiosidad de la cual nos ha sido difícil despojarnos. Desde nuestra perspectiva, qué duda cabe, hicimos una lectura equivocada de la situación.

No entendimos el rol de la ideología de un sector importante de la sociedad, que no estaba en condiciones de aceptar la radicalización de la "vía chilena al socialismo"; que no quería seguirnos en nuestra propuesta de cambio; que deseaba seguridad, por sobre el salto histórico que pretendíamos. La prudencia y la apertura a otras fuerzas políticas a la que llamaba Salvador Allende, no fue escuchada por nosotros. El golpe de Estado se hizo, desgraciadamente, inevitable. Nuestra frágil democracia, muy autoritaria y disciplinada, amante más del orden que de la libertad, se derrumbó.

Sus consecuencias aun las vivimos: la prisión política, la tortura, la desaparición forzada de personas y la represión, fueron una práctica institucional del Estado que ha quedado demostrada fehacientemente por el Informe de la Comisión Rettig, las conclusiones de la Mesa de Diálogo y el reciente informe de la Comisión Valech. Determinar la responsabilidad intelectual y material sobre estos lamentables hechos, debe seguir siendo tarea de los Tribunales de Justicia.

El Presidente de la República ha dicho: "el quiebre de la democracia y de las bases de nuestra convivencia se produjo en medio de tormentas políticas e ideológicas que no fuimos capaces de controlar. La ruptura de la institucionalidad y la instauración de la arbitrariedad y el terror fueron la consecuencia de esos errores colectivos".

Por su parte, el Comandante en Jefe del Ejército, don Juan Emilio Cheyre, ha señalado: “ ¿Excusa el escenario de conflicto global ya descrito las violaciones a los derechos humanos ocurridas en Chile? Mi respuesta es única e inequívoca: no. Las violaciones a los derechos humanos, nunca y para nadie, pueden tener justificación ética". Tal como lo expresé hace unos días en una carta pública dirigida al general Cheyre y que cito textual: "yo fui uno de los muchos chilenos detenidos y torturados después del golpe militar. Y aunque la violación a los Derechos Humanos tiene una enorme repercusión en la vida personal de quien la sufre y deja un dolor que no disminuye, debo decirle que su declaración acerca de la responsabi- 
lidad del Ejército en estos hechos es un gran paso. Tremendamente positivo, desde todo punto de vista". El reconocimiento sincero de estos acontecimientos, la verdad sobre los mismos y la acción reparadora de la justicia, permitirán reconocernos en una misma comunidad nacional, restañar las heridas y reconciliar los espíritus. Esto implica entre otras cosas, entender que los Derechos Humanos son el patrimonio básico que debe inspirar a todas las corrientes políticas y el diálogo de civilizaciones en el siglo XXI $\mathrm{y}$ en cuyo marco todos, sin ambages, deben condenar el terrorismo venga de donde venga, cualquiera sea su fundamento ideológico o religioso.

Ello supone instituciones armadas que recuperen definitivamente su ascendiente sobre el conjunto de la sociedad chilena. La hora actual nos obliga a pensar en conjunto el futuro de Chile. A fortalecer su democracia. A ampliar las fronteras de la libertad. A fomentar el respeto mutuo y la tolerancia. A terminar con la exclusión social, la pobreza y las discriminaciones.

A que asumamos que Chile es un país plural y que en su diversidad debemos construir un destino común. El Ejército de Chile, nacido en los albores de nuestra Independencia, es una institución permanente de la patria y representa los valores más caros de nuestra vida republicana. En él queremos reconocernos, sin distinción, todos los chilenos independientemente de su signo político, ideológico o religioso.

Estamos en esa senda. Se requiere no desviarnos del camino.

Muchas gracias. 


\title{
PONENCIA EN PANEL: \\ "EL IMPACTO DE LAS IDEOLOGÍAS EN EL RESPETO DE LOS DERECHOS HUMANOS EN EL SIGLO XX"*
}

\begin{abstract}
Andrés Allamand
Quiero comenzar por agradecer la invitación a participar en este importante seminario, que sin duda será otro paso importante en la tarea que el Ejército se ha impuesto al incorporar en su doctrina el firme respeto a los derechos individuales.

El éxito de tal incorporación, que es un cambio cultural mayor, depende críticamente, desde mi punto de vista, de dos factores: primero, de la forma en que se aprecie el impacto de las ideologías en el siglo que dejamos atrás, ya que éstas influyeron en la forma en que el Ejército apreció el tema de los derechos humanos, y segundo, de la manera en que se resuelvan las situaciones que afectan hoy al Ejército, ya que el actual escenario político y judicial influirá en el éxito y la fluidez del proceso.

¿Qué agregar a lo que ya se ha señalado acerca del impacto de las ideologías? Solamente insistir en un punto: que el conflicto fundamental del siglo XX fue el antagonismo entre la democracia y las diversas formas de autoritarismos y/o totalitarismos, hoy en retirada. Las ideologías que se apartaron, despreciaron o aspiraron a sustituir la democracia tienen en común dos rasgos: el desprecio por el derecho y la apelación a la fuerza. Y quizás un tercero: la utopía de creer que la fuerza separada del derecho es controlable. Sin embargo, la historia se encarga de demostrar una y otra vez, que la fuerza termina autonomizándose, desbordando los frágiles marcos en que - ante la ausencia del derecho - se la pretende encasillar. La fuerza apartada de la ley es un animal indomesticable que obnubila y deshumaniza a quienes la poseen. ¿Por qué deshumaniza? Porque lo único que garantiza una vida propiamente humana, no azotada por la violencia, es la existencia de una comunidad política, en que sólo el poder legítimo se vale de la fuerza.

Cuando la comunidad política se fractura, es la fuerza la que pasa a dominar al poder político. De allí la necesidad de cuidar todos los elementos que conforman una comunidad política, teniendo siempre a la vista su

* Texto completo de la exposición del abogado y miembro del partido Renovación Nacional, Andrés Allamand, en el foro sobre el impacto que tuvieron las ideologías en el respeto de los derechos humanos en el siglo XX, que tuvo lugar en el marco del seminario "Ejército y Derechos Humanos, Compromiso para el Siglo XXI", organizado por el Ejército de Chile en la Escuela Militar, Santiago, el 7 de diciembre de 2004. (N. del E.)
\end{abstract}


fragilidad endémica. Detrás de todo conflicto social violento, detrás de todo abuso a la integridad humana siempre se divisa una comunidad política — local, nacional o incluso supranacional — que no fue adecuadamente cuidada y protegida.

Considerando mis muchas coincidencias con quienes me han antecedido, y a fin de no reiterar innecesariamente conceptos, pretendo ocuparme de aspectos que son más coyunturales, pero que, en mi opinión, no pueden dejar de abordarse, desde un punto de vista académico.

El Ejército después del Informe de la Comisión sobre Prisión Política y Tortura

En este punto debo comenzar realzando la importancia del Informe sobre Prisión Política y Tortura. Era un paso doloroso, pero necesario. Habla de enfrentar la verdad. En segundo lugar, hay que dejar constancia que el país entero ha condenado frontalmente la tortura. Más aún, ha quedado en claro que el contexto histórico no justifica la violación de los derechos humanos. En tercer término, hay que destacar también la sabia orientación que el Presidente Lagos le ha dado al Informe.

Él ha dicho que el propósito de éste es "sanar las heridas, no reabrirlas”. Pero ¿qué falta para sanar las heridas y no reabrirlas? ¿Cuántas personas, en esta sala y fuera de ella, están fundadamente preocupadas de que el país esté caminando a una reapertura de las heridas que debemos sanar? En mi opinión, el compromiso con el respeto a los derechos individuales y el rechazo a toda ideología que se aparte de tal matriz es lo que al Ejército le corresponde hacer. Pero hay otros elementos que deben provenir de la sociedad — de sus autoridades, organismos y ciudadanos — para ayudar a que el proceso culmine como el país necesita.

Estos elementos son a lo menos cuatro:

\section{Que la verdad sea completa.}

El Presidente Lagos, al dar a conocer el Informe sobre Prisión Política y Tortura, se preguntó: “¿Cómo explicar tanto horror? ¿Qué pudo producir conductas como las que allí aparecen? No tengo respuesta frente a ello”. Esas fueron sus palabras. ¿Puede quedar en el aire esa pregunta? No, no puede.

Primero, porque si el país resuelve ignorar los hechos que generaron el horror siempre quedará expuesto a repetirlos. Y segundo, porque todos sabemos cuáles causas generaron el horror y no hay ninguna razón para no 
expresarlas en forma clara. El horror no apareció de la noche a la mañana. Se fue gestando a la par del socavamiento de la democracia chilena, de la validación de la violencia política, del irresponsable entusiasmo revolucionario por la vía armada, de la alimentación sistemática del odio de clases, del pesado influjo de la "guerra fría", en fin, de la "borrachera ideológica" que asesinó la tolerancia entre nosotros.

Y cuando se fracturó la comunidad política - proceso en el cual ninguna responsabilidad tuvieron las Fuerzas Armadas- ellas se vieron obligadas a actuar, pero lo hicieron con una violencia prolongada e injustificable. Este proceso constituyó la tragedia de Chile. Hace unos días el Obispo Valech decía que "debemos preguntarnos qué responsabilidad tenemos todos en lo que pasó en Chile". Pues bien, debemos hacerlo sin miedo. Habrá responsabilidades directas e indirectas, remotas y cercanas, principales y accesorias, por acción u omisión, penales, legales, políticas y morales.

Hay que diferenciarlas para evitar aquello de que como todos fuimos responsables nadie fue responsable y, también, para romper con el círculo vicioso de las justificaciones recíprocas. ¿En qué consiste el círculo vicioso? Desde una vereda, algunos dirigentes que proclamaban su adhesión a la vía violenta y amenazaban con la dictadura del proletariado, se escudan ahora en que todo eso fue una exageración retórica y que no tuvieron ninguna responsabilidad en los volcánicos procesos políticos que ellos mismos desataron.

¿Y qué ocurre en la vereda del frente? Digámoslo también claramente. Algunos partidarios del gobierno militar y algunos antiguos mandos de las FF.AA. argumentan que se vieron envueltos en una situación para la cual no estaban preparados, que las violaciones a los derechos humanos eran inevitables y que, por ende, tampoco tienen responsabilidades en lo sucedido. Luego de 30 años el país sigue entrampado en un juego infecundo y simétrico de exculpaciones que se expresa así: "Como yo no tuve culpa en lo que ocurrió antes, estoy eximido de lo que pasó después. Como fui víctima de lo que pasó después, estoy eximido de lo que pasó antes". Ambas premisas son falsas. El problema es que desde esa bruma emerge un interesado aprovechamiento político.

Yo nunca participé en el gobierno militar; es más, viví algunos momentos amargos cuando hace años planteaba que debían reconocerse y repararse las violaciones a los derechos humanos y que había que depurar la Constitución de 1980 de injertos autoritarios que inevitablemente mantendrían en el campo de la política contingente a las FF.AA. 
Por lo mismo creo tener alguna autoridad para rechazar la estigmatización política y la descalificación moral de todos aquellos que, con distintas intensidades y en diferentes posiciones, apoyaron y trabajaron en el gobierno militar, partiendo por quienes integraban las Fuerzas Armadas. Además, la vida y la historia se tejen a partir de paradojas y claroscuros. Y, en tal sentido, nadie debiera olvidar que el Ejército de 1978, el mismo que a algunos presentan como una horda inhumana y desquiciada, no sólo es el de Maipú, Yungay y La Concepción, sino también aquel que con inferioridad de medios pero gran coraje, impidió ese mismo año 1978 una agresión externa inminente.

Este tema no es menor: la verdad mutilada no ayudará a reconstituir la comunidad política, no le abrirá camino a la reconciliación, no facilitará el pleno reencuentro del Ejército con la sociedad y tampoco facilitará la adopción de sus nuevos códigos de conducta.

2. Que se adopte una nueva aproximación al tema de las responsabilidades políticas.

Desde la cátedra universitaria se enseña que hay dos maneras de entender la responsabilidad. Una es la responsabilidad que se exige. La otra es la responsabilidad que se asume. La responsabilidad que se exige es un concepto jurídico, supone que alguien ha sido dañado y tiene derecho a reclamar de su agresor una reparación.

Pero, tal noción, trasladada al campo político, es del todo inoperante para avanzar en la reconciliación. La responsabilidad como exigencia es la médula del círculo vicioso en que nos encontramos. Los adversarios del gobierno militar demandan que todos quienes participaron en éste se reconozcan responsables por lo ocurrido en materia de derechos humanos.

A su vez, los partidarios del gobierno militar responden que quienes deben asumir su responsabilidad son aquellos que provocaron las condiciones en las cuales se produjeron las violaciones a los derechos humanos. Estos últimos retrucan diciendo que la demanda que se les formula tiene por objeto únicamente justificar lo ocurrido. La respuesta no tarda un segundo: quienes sembraron los vientos no pueden quejarse de las tempestades. ¡Esa argumentación no lleva a ninguna parte! Lo que corresponde es que cada sector piense en la responsabilidad, no como una exigencia que le formula un contradictor, sino como un deber ser, exista o no alguien con título legítimo para reclamarla.

La responsabilidad que se asume —en contraposición a la responsabilidad que se exige- es un acto voluntario, unilateral, veraz y autocrítico. La responsabilidad que se asume es propiamente política y se distingue del 
perdón en cuanto es éste un acto personal y de carácter eminentemente moral y, por lo tanto, no exigible. Nadie puede ser obligado a perdonar y el perdón que se pide por obligación carece de todo significado.

Asumir la responsabilidad engrandecería a la clase dirigente, transparentando lo que es evidente para la inmensa mayoría de Chile. La ciudadanía no ignora que la Unidad Popular llevó al país al borde del abismo, ni ignora que las autoridades del gobierno militar no evitaron las violaciones a los derechos humanos; no ignora que los Tribunales se apoyaron en formalismos para no brindar la protección que les fue requerida, ni que la prensa fue tímida para denunciar los abusos.

Lo que ayudaría a la reconciliación es que los protagonistas de los últimos 30 años (40 dirán algunos) asuman sus responsabilidades no como un juego de contraprestaciones y coartadas recíprocas, sino como un acto de franqueza y de reconstitución de los vínculos de la comunidad política que es Chile. Que cada cual deje de sermonear al adversario respecto de lo que éste debe o no debe hacer y simplemente cumpla con su deber.

\section{Que se entienda bien el significado de "El fin de una visión" y} las responsabilidades institucionales. El documento "El fin de una visión" es una cabal expresión de la responsabilidad que se asume*. Una gran mayoría del país lo ha aplaudido, pero muchos partidarios del gobierno militar lo han criticado, aduciendo que fue un error o una demostración de debilidad, y que la declaración debió ser "negociada". Pues bien, todas esos razonamientos se inspiran en la lógica de la responsabilidad que se exige y no captan el valor intrínseco de la responsabilidad que se asume.

Además, "El fin de una visión" era indispensable simplemente porque la tesis de que las violaciones a los derechos humanos fueron el resultado de "excesos individuales" era inaceptable y absurda. Era intelectualmente inaceptable porque es inverosímil que se trate de excesos individuales cuando las prácticas duran años y en ella se comprometen numerosas personas y recursos institucionales. Era conceptualmente absurda porque choca de frente con el jamás cuestionado carácter profesional, jerárquico y disciplinado de las FF.AA. Hace mucho tiempo que debió abandonarse esa tesis.

Es un grave error para cualquier institución argumentar eludiendo la verdad. Y el costo en prestigio que pagan las instituciones por hacerlo es enorme. Por otro lado, la tesis de los "excesos individuales" ignoraba la

* El texto de "El Ejército: Fin de una Visión" aparece reproducido en esta edición en el documento "Informe de la Comisión Nacional de Prisión Política y Tortura, y Respuestas Institucionales". (N. del E.) 
evidente responsabilidad de los mandos involucrados. Bajo tal tesis nadie era responsable de lo ocurrido, pero sería completamente erróneo saltar al extremo opuesto y sostener que todos los miembros de las Fuerzas Armadas tuvieron responsabilidad en lo ocurrido.

Yo estoy seguro que la inmensa mayoría nada tuvo que ver con esas prácticas y durante todo el régimen militar asumió con abnegación sus tareas profesionales y/o desempeñó cargos desde donde contribuyó a la modernización del país. Ellos no tienen ninguna responsabilidad por lo ocurrido y así el país debe reconocerlo.

Por último, el reconocimiento ahora de su responsabilidad institucional ¿supone que antes las FF.AA. hayan incorporado a su doctrina tales prácticas aberrantes? Categóricamente no. Hacer suya una doctrina exige validarla hacia adentro y hacia fuera. Y ni una ni otra cosa jamás ocurrió en nuestro país.

Lo que pasó fue que algunos altos mandos se apartaron de la doctrina y arrastraron a subordinados que no quisieron, no supieron o no pudieron oponerse.

4. Que se avance en la verdad y se salga del pantano jurídico. No podría terminar estas reflexiones sin una breve alusión a los aspectos judiciales que hoy afectan a las FF.AA. Asumo desde ya, que sólo abordar el tema me acarreará la acusación de querer favorecer la impunidad. Basta ver el calibre de las descalificaciones que recibe a diario la Sra. Presidenta del Consejo del Estado por defender la aplicabilidad de la llamada "amnistía impropia". Me interesa destacar que la clase dirigente ha ido asumiendo con fatalismo que nada puede o debe hacer en esta materia y que la solución (de haber alguna) tendrá que emanar algún día, desde los estrados judiciales.

De este modo la dirigencia vuelve a fracasar: antes no fue capaz de impedir la tragedia y ahora tampoco es capaz de arbitrar los medios para salir de ella, para "sanar las heridas". Así, se aferra a vías judiciales para resolver problemas que obviamente tienen marcadas aristas políticas. ¿Y qué hace el Poder Judicial? Simplemente lo opuesto. Nada ejemplifica mejor lo expuesto que la bizantina tesis del secuestro permanente. El propio Presidente de la Corte Suprema ha señalado que la fórmula adoptada es contraria el sentido común. No sólo eso. Vulnera el debido proceso decretar que no es al Estado al que le corresponde probar que un delito permaneció en el tiempo, sino que a los inculpados corresponde probar que ello no ocurrió. Las cosas claras, la Corte Suprema puede en definitiva resolver aplicar o no la amnistía, pero lo que no puede hacer es valerse de un 
pretexto para no hacer ni una ni otra cosa. Permítanme una predicción: con la tesis del "secuestro permanente" al Poder Judicial le pasará lo mismo que a las FF.AA. con la tesis de los "excesos individuales". Por ser sólo una ficción sin sustancia, deberá abandonarla y entonces pagará el costo de haberla adoptado.

Además, la actual situación es, en la perspectiva de obtener la información que pueda faltar sobre el paradero de los detenidos desaparecidos, lo más contraindicado. No hay incentivo para ello y todas las fórmulas legislativas que los Presidentes Aylwin, Frei e incluso Lagos han intentado para avanzar por un camino de verdad, reparación y justicia, no han prosperado simplemente por el bloqueo parlamentario. ¿Y cuál es el resultado de todo ello? Mantener a las actuales FF.AA. como rehenes del pasado, lo que no es razonable cuando éstas han demostrado que no aspiran a olvidarlo sino que, al revés, han aprendido de él.

\section{Palabras finales}

El país está entrando a una nueva etapa. El compromiso del Ejército con los derechos humanos es uno de los elementos más importantes para terminar de reconstituir la comunidad política fracturada hace más de tres décadas. Es un proceso de envergadura mayor. A ese proceso también ayudará el conjunto de reformas constitucionales recientemente acordadas, que terminan con instancias y mecanismos que involucraban a las FF.AA. en la contingencia política.

El Ejército y la sociedad están dejando atrás una etapa de dolorosa excepcionalidad, en que hubo duros enfrentamientos entre aquél y parte de ésta. Es obvio, pero Chile tiene sólo un Ejército y una sociedad. El único destino de ambos es la fusión. A mí nunca me ha convencido aquello del "mundo civil" y el "mundo militar" como esferas separadas. Un país con un Ejército aislado es, por definición, vulnerable e impredecible.

El asunto es que la civilidad y la clase dirigente pueden ayudar o entorpecer tal proceso. El General Prats, cuya memoria ha hecho bien el Ejército en reivindicar, alguna vez aludió al "sordo rencor" que se incubó durante años al interior de las FF.AA., gatillado por la incomprensión de los civiles acerca de sus angustias y legítimas inquietudes. Chile no debiera reiterar ese error.

Muchas gracias. 